\title{
The characterisation of the interfacial chemistry of adhesion of rigid polyurethane foam to aluminium
}

\author{
Kyoko Shimizu $^{1 *}$, Marie-Laure Abel ${ }^{1}$, Christopher Phanopoulos ${ }^{2}$, Servaas Holvoet ${ }^{2}$ \\ and John F. Watts ${ }^{1}$ \\ ${ }^{1}$ Surrey Materials Institute and Faculty of Engineering \& Physical Sciences, \\ University of Surrey, Guildford, Surrey, GU2 7XH, UK \\ ${ }^{2}$ Huntsman, Everslaan 45, B-3078 Everberg, Belgium \\ *E-mail address: k.shimizu@ surrey.ac.uk
}

\begin{abstract}
The interfacial interactions between rigid polyurethane foam (RPUF) and aluminium have been studied to understand adhesion mechanisms. Three different blowing systems are used in the production of the foam: chemical blowing, physical blowing and a mix of chemical and physical blowing systems. In addition an unfoamed system has been examined for comparison of the catalysts behaviour with and without blowing agents and the surfactant. Peeled failure surfaces have been examined by Xray photoelectron spectroscopy (XPS) and time of flight secondary ion mass spectrometry (ToF-SIMS). To examine the intact interfacial regions of RPUFs cured against aluminium, samples have been sectioned by microtomy. The failure surfaces of the aluminium sides exhibit relatively clean aluminium surfaces with RPUF residues observed for all three foamed systems; such thin RPUF layers (ca. $1 \mathrm{~nm}$ ) indicate good adhesion (and a cohesive failure) between foam and substrate and that the interfacial adhesion is higher than the cohesive strength of the foam. The unfoamed systems behave in a similar manner but have a higher peel strength. A fragment indicative of covalent bond formation between isocyanate and aluminium (nominal mass at $102 \mathrm{u}: \mathrm{AlCHNO}_{3}{ }^{-}$) is observed on the failure surface of aluminium side, where RPUF/aluminium interface region is present, for all foams. The catalyst used in these formulations, pentamethyldiethylenetriamine (PMDETA), is concentrated at the interface area. Whilst examination of the sectioned specimens shows that the silicone surfactant is concentrated within the cell area fulfilling its role
\end{abstract}


on cell foamation and stabilisation, and is not segregated at the RPUF/aluminium interface.

\section{Introduction}

RPUFs are widely used in many industries, especially construction, because of their low thermal conductivity, good adhesion, good dimensional stability and excellent mechanical strength at low densities ${ }^{1}$. The objective of this work is to gain better understanding of the adhesion mechanism between polyurethane and aluminium in order to improve adhesion performance. Three different blowing systems are used in the producing of the foams, chemical blowing, physical blowing and a mix of chemical and physical blowing systems; in this paper their interfacial chemistries with aluminium are compared. In the chemical blowing system, water is widely used as the blowing agent and carbon dioxide is generated by the reaction of isocyanate with water. In the physical blowing system, the exothermic reaction of isocyanate with polyol produces urethane linkages followed by the vaporising of blowing agent and the resulting gas being trapped in the closed cell foams ${ }^{2}$. The excessive use of water leads to cell deformation by the rapid diffusion of carbon dioxide through the cell wall $^{3}$. Therefore, in the case of the majority of RPUFs, there is a need for physical blowing agents due to requirements of dimensional stability to maintain closed cell structure and low thermal conductivity ${ }^{1}$. RPUFs are prepared from polymeric methylene diphenyl diisocyanate (PMDI), polyol, silicone surfactant, amine catalysts and blowing agents. The kinetics of the foam formation are followed by cream time, gel time, tack-free time and end-of-rise time ${ }^{1,3-4}$. The cream time is the beginning point of the foam rise and thus the colour of the mixture changes to cream from dark brown as a result of the generation of gas by the blowing agent. The gel time is the starting point of stable polymer network formation via urethane and urea linkages and intensive allophonate and biuret crosslinking and branching, respectively. The tackfree time is when the outer surface of the foam looses its stickiness as a result of crosslinking and the end-of-rise time is the point where the foam reaches its maximum height. The rates of blowing and gelling reactions are important factors for the kinetics of the foaming process. If the gas generation is too fast, the foam initially expands well but then collapses as a result of lack of gelling process to retain the gas 5 . The blowing reaction promotes the faster cream time, while the gelling reaction 
promotes the faster gel time and tack free time. The foam properties also depend on the types of polyols, amount of surfactants and blowing agents ${ }^{3,5-8}$. The kinetics of the foam formation in this work has been adjusted to have a similar time for all three foamed system by changing the catalysts concentration.

In previous work, interfacial chemistry of single component PMDI with aluminium was studied using XPS and ToF-SIMS ${ }^{9}$. It was shown that water reaction occurs both at the surface of PMDI and at the interface between PMDI and aluminium. At the interface, there is a limit on the yield of reaction with water and the water reaction is completed within a short period of time because of the finite amount of hydroxyl groups on the aluminium surface, while the PMDI surface continues to react with water from atmospheric moisture. In this work, characterisation of interfacial interaction between RPUFs and aluminium has been studied by employing two different methodologies. The first method is that the interfacial failure surfaces after peel test were examined using surface analysis techniques. The second one is employing an ultra low-angle microtomy (ULAM) technique for sample preparation in combination with ToF-SIMS, which allows investigation of the buried polymermetal interface without mechanical perturbation.

\section{Experimental}

\subsection{Raw materials}

The raw materials required to synthesize RPUFs are isocyanate, polyol, catalysts, surfactant and blowing agents. The isocyanate used was PDMI which was reacted with polyether polyol; additional reagents in the formulation were pentamethyldiethylenetriamine (PMDETA) as a strong blowing catalyst, dimethylcyclohexyl amine (DMCHA) as a balancing between gelling and blowing catalyst, and polydimethylsiloxane as a silicone surfactant. All were provided by Huntsman Holland BV, The Netherlands. A pentafluorobutane/ heptafluoropropane blend was used as a physical blowing agent and supplied by A-Gas Ltd, UK (product designation HFC $365 \mathrm{mfc} / 227 \mathrm{ea}$ ), while deionised water was used as a chemical blowing agent. Structures of these chemicals are shown in Figure 1. 


\subsection{Synthesis of RPUFs}

The RPUFs were synthesised by a two shot method, all raw materials except PMDI were mixed together and shaken for $10 \mathrm{~min}$. Subsequently, PMDI was added and mixed at $2000 \mathrm{rpm}$ for 6 seconds using a high-speed stirrer. The reactant mixtures were poured onto thin aluminium foils (14 $\mu \mathrm{m}$ thickness) and cured overnight. Three different blowing systems were used to synthesize the RPUFs as described in Table 1. The chemical blowing agent, deionised water, was used to make Foam 1. Foam 2 was produced using a mix of the chemical and the physical blowing agents, and Foam 3 was made using the physical blowing agent, HFC $365 \mathrm{mfc} / 227$ ea and a very small amount of deionised water. The NCO index, which is a ratio of NCO (PMDI) to OH (polyol and water) concentrations, was fixed at 1.1. Therefore, the amount of PMDI decreased with decreasing the amount of water from Foam 1 to Foam 3, and the amount of catalysts was increased to compensate for the cure rate differences. In the formulation process, the cream time was 9-10 s; the full cup time, when the foam volume rises to full cup of $500 \mathrm{ml}$, was $34-41 \mathrm{~s}$, the gel time was $57 \mathrm{~s}$ and the end-ofrise time was 100-105 s for all RPUFs.

An unfoamed sample was prepared with PMDI, polyol, PMDETA and DMCHA. The same amount of PMDETA and DMCHA as in Foam 1 was used, and the NCO index was fixed at 1.1. All PMDI and 30 wt. \% of polyol amount were mixed in advance; subsequently the rest of the polyol mixture with PMDETA and DMCHA was added to them and mixed using the high-speed stirrer. The reactant mixture was poured onto the thin aluminium foil and cured overnight.

\subsection{Ultra Low-Angle Microtomy (ULAM)}

Before using ULAM, samples were mounted into epoxy resins (EpoFix) and cured overnight. These samples were cut into small pieces, approximately $10 \times 5 \times 2 \mathrm{~mm}^{3}$. ULAM was employed to expose the RPUF/aluminium interfacial region. Details of the concept of the ULAM operation are explained elsewhere ${ }^{10-11}$. The ULAM processing of samples was carried out on a Microm HM355S motorized rotary microtome (Optech Scientific Instruments, Thame, UK) equipped with a standard specimen clamp and a tungsten-carbide knife. The ultra low angle tapers through the RPUF/aluminium samples employed here were produced using an ultra-low angle 
sectioning block $\left(3.5 \times 3.5 \times 0.7 \mathrm{~cm}^{3}\right)$, which have one $3.5 \times 3.5 \mathrm{~cm}^{2}$ tapered face raised by a height of $200 \mu \mathrm{m}$ relative to the parallel edge of the tapered face, giving a nominal taper angle of $0.33^{\circ}$. Actual samples, however, had a higher angle than $0.33^{\circ}$ as a result in difficulty in cutting the mounted samples parallel to the very thin aluminium foil. Taper angles of each sample were calculated by measuring the exposed aluminium substrate thickness using optical microscopy compared to the actual thickness of the foil measured by a micrometer. The taper angles of Foam1, 2, and 3 were $17^{\circ}, 21^{\circ}$ and $11^{\circ}$, respectively.

\subsection{XPS analysis}

XPS analysis was achieved using a Theta Probe spectrometer (THERMO FISHER SCIENTIFIC, East Grinstead, UK). The analyser was operated in the constant analyser energy (CAE) mode at a pass energy of $300 \mathrm{eV}$ with a step size of $0.4 \mathrm{eV}$ for the survey spectra and a pass energy of $150 \mathrm{eV}$ with a step size of $0.1 \mathrm{eV}$ for high resolution spectra of the elements of interest. A monochromated Al Ka X-ray at power of $140 \mathrm{~W}$ with a spot size of $400 \mu \mathrm{m}$ in diameter was employed for analyses. Charge compensation was achieved using an electron flood gun, and also a binding energy (BE) of $285.0 \mathrm{eV}$ for $\mathrm{C}-\mathrm{C} / \mathrm{C}-\mathrm{H}$ components of $\mathrm{C} 1 \mathrm{~s}$ peak has been used as reference for charge correction. The spectrometer was controlled by datasystems based on Thermo Fisher Scientific's Avantage software (v.4.37) for spectral acquisition and subsequent dataprocessing. The surface composition of the specimens are obtained from high-resolution spectra following non-linear background subtraction using sensitivity factors and the transmission function correction supplied with the Avantage datasystem.

\subsection{ToF-SIMS analysis}

ToF-SIMS analysis was achieved using a TOF.SIMS 5 (ION-TOF GmbH, Münster, Germany). Static SIMS conditions with a total ion dose less than $1 \times 10^{13}$ ions $\mathrm{cm}^{-2}$ analysis ${ }^{-1}$ were employed using a $9.5 \mathrm{keV} \mathrm{Bi}_{3}{ }^{+}$primary ion beam operating in the high current bunched mode for high spectral resolution ${ }^{12}$. An analysis area of $100 \times 100$ $\mu \mathrm{m}^{2}$ at a resolution of $64 \times 64$ pixels was used. ToF-SIMS images were acquired over a $500 \times 500 \mu \mathrm{m}^{2}$ at a resolution of $128 \times 128$ pixels, at one cycle per pixel with a total 
of 100 scans. A cycle time of $200 \mu$ s was employed. ToF-SIMS spectra were acquired over a mass range of 1-850 $\mathrm{u}$ in both positive and negative ion modes. Charge compensation was achieved using a pulsed electron flood source. Fragments of known composition, such as $\mathrm{H}^{+}, \mathrm{CH}_{3}{ }^{+}, \mathrm{Na}^{+}, \mathrm{H}^{-}, \mathrm{C}^{-}, \mathrm{O}^{-}$and $\mathrm{OH}^{-}$were used for mass calibration. In addition, fragments characteristic of aluminium and the raw materials of RPUF were also used.

The ToF-SIMS intensities for particular fragment ions under consideration are evaluated using the concept of relative peak intensity (RPI), which is the ratio of the intensity of the ion of interest relative to the total ion intensity from $\mathrm{m} / \mathrm{z}=1$ to 850 $\mathrm{u}^{13}$ :

$$
\mathrm{RPI}_{\mathrm{x}}=\mathrm{I}_{\mathrm{x}} / \mathrm{I}_{\text {total }} \quad<1>
$$

where $\mathrm{x}$ is the ion of interest and $\mathrm{I}_{\text {total }}$ is the total ion intensity between $\mathrm{m} / \mathrm{z}=1$ and $850 \mathrm{u}$, and $\mathrm{I}_{\mathrm{x}}$ is the measured intensity of the ion under consideration.

\section{Results}

\subsection{Reference samples}

The raw materials were examined by ToF-SIMS in order to have references for the interpretation of ToF-SIMS data. These samples are produced by deposition of a thick layer on a degreased aluminium substrate. Figure 2 shows the positive ToFSIMS spectra in the mass range of $\mathrm{m} / \mathrm{z}=1-210 \mathrm{u}$ of the raw material samples. From the PMDI sample, a high intensity of a fragment of the isocyanate functional group $(\mathrm{m} / \mathrm{z}=132 \mathrm{u})$ is observed, and a fragment of an amine functional group $(\mathrm{m} / \mathrm{z}=106 \mathrm{u})$, which originates from the reaction product of PMDI exposed to atmospheric moisture before the analysis, is also observed at low intensity ${ }^{9}$. For the polyol sample, high intensities of oxygen containing fragments such as $\mathrm{C}_{4} \mathrm{H}_{7} \mathrm{O}_{2}{ }^{+}(\mathrm{m} / \mathrm{z}=87 \mathrm{u}), \mathrm{C}_{5} \mathrm{H}_{9} \mathrm{O}_{2}{ }^{+}$ $(\mathrm{m} / \mathrm{z}=101 \mathrm{u}), \mathrm{C}_{6} \mathrm{H}_{9} \mathrm{O}_{2}{ }^{+}(\mathrm{m} / \mathrm{z}=113 \mathrm{u})$ and $\mathrm{C}_{8} \mathrm{H}_{15} \mathrm{O}_{3}{ }^{+}(\mathrm{m} / \mathrm{z}=159 \mathrm{u})$ are observed. For the catalyst samples, characteristic PMDETA fragments are observed at $\mathrm{m} / \mathrm{z}=58 \mathrm{u}$ $\left(\mathrm{C}_{3} \mathrm{H}_{8} \mathrm{~N}^{+}\right), 72 \mathrm{u}\left(\mathrm{C}_{4} \mathrm{H}_{10} \mathrm{~N}^{+}\right)$and $129 \mathrm{u}\left(\mathrm{C}_{7} \mathrm{H}_{17} \mathrm{~N}_{2}{ }^{+}\right)$, while characteristic DMCHA fragments are found at $\mathrm{m} / \mathrm{z}=58 \mathrm{u}\left(\mathrm{C}_{3} \mathrm{H}_{8} \mathrm{~N}^{+}\right)$and $\mathrm{m} / \mathrm{z}=126 \mathrm{u}\left(\mathrm{C}_{8} \mathrm{H}_{16} \mathrm{~N}^{+}\right)$; although XPS results show the presence of a degree of contamination and/or oxidation, the molecular specificity of SIMS enables unambiguous assignment of specific ions to 
their parent molecules. Typical siloxane fragments are observed at $\mathrm{m} / \mathrm{z}=73 \mathrm{u}$ $\left(\mathrm{C}_{3} \mathrm{H}_{9} \mathrm{Si}^{+}\right), 147 \mathrm{u}\left(\mathrm{C}_{5} \mathrm{H}_{15} \mathrm{OSi}_{2}{ }^{+}\right)$and $207 \mathrm{u}\left(\mathrm{C}_{5} \mathrm{H}_{15} \mathrm{O}_{3} \mathrm{Si}_{3}{ }^{+}\right)$are obserbed on the silicone surfactant sample.

\subsection{Peel testing and failure surfaces}

Samples were cut into small pieces and the organic phases were carefully manually peeled from the substrates. This procedure was carried out as a means to producing failure surfaces for surface analysis, however a qualitative estimation was made of the relative peel strengths of the four polyurethane/aluminium systems. The unfoamed sample exhibits the highest peel strength, and peel strengths of Foams 1 and 2 are similar while that of Foam 3 is slightly lower. All failure surfaces exhibit smooth and homogeneous surfaces, and no cavities are observed. Densities of all Foams are similar but the density of Foam 3 is slightly lower than other Foam 1 and 2, and this may affect the lower peel strength. After peel testing, failure surfaces were examined by XPS and ToF-SIMS.

Figure 3 shows XPS survey spectra of bulk (obtained by sectioning the RPUF) and failure surfaces of Foam 1. Table 2 shows the surface composition of all foams and the unfoamed systems and the interfacial failure surfaces, and of this aluminium foil. The bulk of foam has many cavities, which are generally called cells, so these analysis areas of bulk foams may include surfaces of cells as well, and certainly do for the bulk analysis where the sample has been sectioned parallel to the substrate. The physical blowing agent, HFC 365fmc/227ea, was used to synthesise Foam 2 and Foam 3, however, fluorine was not observed on either sample. This is probably because the blowing agent has evaporated upon curing or has been pumped out in the vacuum of the XPS instrument. Silicon peaks are observed on the bulk surface of all foams, while no silicon peaks are observed on either side of the failure surfaces. This implies that the silicone surfactant does not segregate into the failure region, but segregates to the internal surfaces of the voids making up the foam. Magnesium peaks are observed on the failure surfaces of all aluminium sides and aluminium foil, and this originates from a small amount of this element from the aluminium substrate which has segregated to the surface during the foil production process. The PU sides of failure surfaces exhibit higher nitrogen and carbon concentrations than the bulk of PU for all foam systems. C1s spectra have been peak fitted to reveal more details of 
the chemical components. Figure 4 shows the $\mathrm{C} 1 \mathrm{~s}$ peak fitting of the bulk and the failure surfaces of Foam 1 and Table 3 shows the carbon peak fitting of the same surfaces for all foams and the unfoamed sample. The first peak at BE $285.0 \mathrm{eV}$ is assigned to hydrocarbon, C-C/C-H/C-Si. The BE of the second peak between 285.8 and $286.1 \mathrm{eV}$ is assigned to $\mathrm{C}-\mathrm{N}$; the third peak between 286.5 and $286.8 \mathrm{eV}$ is assigned to alcohol and/or ether carbon group, $\mathrm{C}-\mathrm{OH} / \mathrm{C}-\mathrm{O} / \mathrm{C}-\mathrm{O}-\mathrm{C}$; the $\mathrm{BE}$ of the forth peak is between 287.7 and $288.3 \mathrm{eV}$ is assigned to carbonyl carbon, $\mathrm{C}=\mathrm{O}$; the $\mathrm{BE}$ of the fifth peak between 289.0 and $289.9 \mathrm{eV}$ is assigned to $\mathrm{N}=\mathrm{C}=\mathrm{O} / \mathrm{N}-$

$\mathrm{CN}=\mathrm{O} / \mathrm{COH}=\mathrm{O} / \mathrm{O}-\mathrm{C}=\mathrm{O}^{14-16}$. The last peak present at the $\mathrm{BE}$ of 291.6 to $292.0 \mathrm{eV}$ is a shake-up satellite resulting from the $\pi \rightarrow \pi^{*}$ transition in the phenyl ring ${ }^{15,17}$.

These failure surfaces and bulk samples of the foams and unfoamed PU systems were examined by ToF-SIMS to obtain molecular information and Figures 5 and 6 present the positive ToF-SIMS spectra of the bulk regions, the failure surfaces of Foam 1, and the unfoamed sample, respectively. Table 4 presents a list of characteristic positive fragments originating from PMDI and the reaction products of PMDI, polyol, DMCHA, PMDETA and silicone surfactant, and component assignments. The PMDI reference sample exhibits a high intensity of the peak at mass $132 \mathrm{u}$ compared with that of the peak at mass $106 \mathrm{u}$. However, the intensity of a fragment of an amine functional group $(\mathrm{m} / \mathrm{z}=106 \mathrm{u})$ is higher than that of a fragment of isocyanate functional group $(\mathrm{m} / \mathrm{z}=132 \mathrm{u})$ for all foam and unfoamed samples. Besides, high intensities of fragments of amine functional groups $(\mathrm{m} / \mathrm{z}=195$ and 197 u) are observed on all PU samples, and these fragments are not observed on the PMDI sample. The fragments of amine functional groups $(\mathrm{m} / \mathrm{z}=106,195$ and $197 \mathrm{u})$ originate from the reaction product of PMDI with water and/or polyol ${ }^{9}$.

\subsection{The RPUF/aluminium interface exposed by ULAM}

The buried interface between the aluminium and the foamed and unfoamed systems was exposed by using ULAM, and ToF-SIMS has been employed to study the interface regions. The interface regions of all foam samples exhibit similar trends. Figures 7 and 8 show high spectral resolution ToF-SIMS images of the Foam 1/aluminium and the unfoamed/aluminium interface regions, respectively. These images were normalised to the total ion signal. Four different regions can be seen on all the foamed samples as exemplified by the images of Figure 7: an aluminium 
substrate region which has high intensities of $\mathrm{Al}^{+}$and $\mathrm{AlO}_{2}{ }^{-}$fragments; an interface region which exhibits a high intensity of $\mathrm{C}_{7} \mathrm{H}_{17} \mathrm{~N}_{2}{ }^{+}$fragment originating from PMDETA; a foam region which has a high intensity of $\mathrm{C}_{7} \mathrm{H}_{8} \mathrm{~N}^{+}$fragment originating from reacted PMDI; and a cell region which has a high intensity of silicone surfactant fragments $\left(\mathrm{C}_{3} \mathrm{H}_{9} \mathrm{Si}^{+}, \mathrm{C}_{5} \mathrm{H}_{15} \mathrm{OSi}_{2}{ }^{+}\right.$and $\left.\mathrm{C}_{5} \mathrm{H}_{15} \mathrm{O}_{3} \mathrm{Si}_{3}{ }^{+}\right)$. Four different regions can be seen on the unfoamed sample, but these regions are clearly different from the ordering observed at the interface of the foam samples: an aluminium substrate region which has a high intensity of $\mathrm{Al}^{+}$fragment; two different compositional interface regions which are the interface regions close to aluminium side and close to unfoamed side; and an unfoamed PU region which has high intensities of $\mathrm{C}_{7} \mathrm{H}_{8} \mathrm{~N}^{+}$(PMDI) and $\mathrm{C}_{6} \mathrm{H}_{9} \mathrm{O}_{2}{ }^{+}$fragments originating from polyol. The interface region close to unfoamed PU side exhibits higher intensities of PMDETA than the interface region close to aluminium side, as shown in Figure $8(\mathrm{~g})$. The reconstructed positive ToF-SIMS spectra of these four coloured regions of Foam 1 and the unfoamed systems are shown in Figures 9 and 10, respectively. The high intensity of $\mathrm{Mg}^{+}$fragment is observed (as a result of the high cross-section of this element in SIMS) at the interface for all samples, however, as magnesium concentration on the aluminium foil surface is relatively small compared with aluminium oxide/hydroxide (XPS data), the reaction of the foam with magnesium can be considered negligible. The ToF-SIMS image of $\mathrm{C}_{8} \mathrm{H}_{16} \mathrm{~N}^{+}$in Figure 7(e) apparently shows a very weak signal from this ion present in the epoxy mount region (on the right hand side of the field of view). However, the $\mathrm{C}_{8} \mathrm{H}_{16} \mathrm{~N}^{+}$fragment is not observed on the epoxy region from high resolution ToFSIMS spectra (not shown) of this region. The signal within the $\mathrm{C}_{8} \mathrm{H}_{16} \mathrm{~N}^{+}$image actually originates from $\mathrm{C}_{8} \mathrm{H}_{14} \mathrm{O}^{+}$within the tail of the main peak of the above fragment as the intensity of $\mathrm{C}_{8} \mathrm{H}_{16} \mathrm{~N}^{+}$peak is very small in the region of analysis. The $\mathrm{C}_{8} \mathrm{H}_{16} \mathrm{~N}^{+}$and the $\mathrm{C}_{8} \mathrm{H}_{14} \mathrm{O}^{+}$fragments are close to each other (a difference of $0.024 \mathrm{u}$ in mass) and it is clear that the high mass tail of $\mathrm{C}_{8} \mathrm{H}_{14} \mathrm{O}^{+}$peak overlaps with the selected $\mathrm{C}_{8} \mathrm{H}_{16} \mathrm{~N}^{+}$peak region. In addition, the absence of the signal on the substrate region also confirms that the signal on the epoxy region is not by smearing of DMCHA. The interface region near the unfoamed side exhibits a high intensity of PMDETA fragment while the interface region close to aluminium side exhibit high intensities of PMDI fragments. 


\section{Discussion}

\subsection{Interface interaction between foams and aluminium}

On the interfacial failure surfaces of foam side for all foam samples, high intensities of carbon, nitrogen and oxygen are observed while no silicon and aluminium are seen in the XPS data. The nitrogen may originate from PMDI, PMDETA and/or DMCHA, and the oxygen peak comes from both PMDI and polyol. ToF-SIMS data show high intensities of PMDI and PMDETA fragments, very small intensities of DMCHA fragments and no silicone surfactant fragments are observed on these surfaces. Characteristic polyol fragment peaks at high masses such as $101 \mathrm{u}\left(\mathrm{C}_{5} \mathrm{H}_{9} \mathrm{O}_{2}{ }^{+}\right)$and 113 $\mathrm{u}\left(\mathrm{C}_{6} \mathrm{H}_{9} \mathrm{O}_{2}^{+}\right)$are not clearly observed on ToF-SIMS spectra. However, XPS data shows the presence of polyol as a result of exhibiting high C-O contents because silicone surfactant has already been excluded as no $\mathrm{Si} 2 \mathrm{p}$ and low $\mathrm{C}-\mathrm{O}$ contents for the amine catalysts. There are polyol peaks at low mass such as $31 \mathrm{u}\left(\mathrm{CH}_{3} \mathrm{O}^{+}\right), 43 \mathrm{u}$ $\left(\mathrm{C}_{2} \mathrm{H}_{3} \mathrm{O}^{+}\right)$and $59 \mathrm{u}\left(\mathrm{C}_{3} \mathrm{H}_{7} \mathrm{O}^{+}\right)$, but these fragments cannot be used unambiguously to characterise polyol as other raw chemicals also exhibit the same fragments. No presence of polyol fragments is observed at high mass indicating that polyols must have reacted with PMDI to form urethane links so in this case it is difficult to identify the large molecules of polyol spectroscopically by ToF-SIMS.

The interfacial failure surfaces of all aluminium sides exhibit very low carbon concentrations and the equivalent thickness of the carbonaceous layer is only 1.1 to $1.2 \mathrm{~nm}$, (calculated using the modified Beer-Lambert equation ${ }^{17-18}$ ). ToF-SIMS data show that high intensities of PMDI and PMDETA fragments and very small intensity of DMCHA fragments are observed whereas no silicone surfactant fragments are observed; there is a very thin layer (ca. $1 \mathrm{~nm}$ ) of foam left after the fracture by peeling of all foam types, indicating that the failure occurs in the foam but extremely close to the interface. The thin foam layer on the failure surface of aluminium side indicates that a cohesive failure has occurred within the RPUF, in agreement with surface thermodynamics of such failures ${ }^{19}$. The thermodynamic work of adhesion, $\mathrm{W}_{\mathrm{A}}$, for the cohesive failure can be described as the work of cohesion of the polymeric phase:

$$
\mathrm{W}_{\mathrm{A}}=2 \gamma_{\mathrm{p}}
$$


where $\gamma_{\mathrm{p}}$ is the surface free energy of the polymeric phase. By contrast, in the case of interfacial failure the $\mathrm{W}_{\mathrm{A}}$ is written by:

$$
\mathrm{W}_{\mathrm{A}}=2 \gamma_{\mathrm{p}}+\pi_{\mathrm{e}}
$$

where $\pi_{\mathrm{e}}$ is the equilibrium spreading pressure. This indicates that the work of adhesion between RPUF and aluminium is greater than the work of cohesion of the foam itself. The adhesion between PU and aluminium is good enough to ensure stress transfer across the interface during peeling. In addition, the bulk of the polymer will be in a more relaxed state as a result of the foamed morphology, but more constrained at the interface at the interface as a result of specific interactions between PU and aluminium. This will also ensure that failure tends towards the interface ${ }^{20}$, chemical heterogeneities may also lead to a localised change in mechanical properties.

The aluminium interfacial failure surfaces expose the interface region of foam/aluminium system. Figure 11 shows the high resolution spectra at nominal mass $102 \mathrm{u}$ for aluminium sides of the failure surfaces for all foams and for the degreased aluminium in the negative mode. Three peaks are observed on the failure surfaces of all foams: the lowest mass peak is $\mathrm{Al}_{2} \mathrm{O}_{3}{ }^{-}$and originates from the aluminium substrate, the highest mass peak is $\mathrm{C}_{7} \mathrm{H}_{4} \mathrm{~N}^{-}$which comes from PMDI, the middle peak is $\mathrm{AlCHNO}_{4}^{-}$which indicates a covalent bond formation between aluminium and PMDI. Details of the peak assignments were described in previous work ${ }^{9}$. By contrast, only $\mathrm{Al}_{2} \mathrm{O}_{3}{ }^{-}$peak is observed on the aluminium foil, and this confirms that the specific bonding is present at the interface between all foams and aluminium.

Comparison of the analyses from the bulk of foam with the failure surface of foam side for all foams, indicates that $\mathrm{C}-\mathrm{N}$ moeties and shake-up satellites diagnostic of aromaticity are higher on the failure surfaces than in the bulk. This indicates that more PMDI is present on the foam failure surfaces than in the bulk foams. The C-N bonding will also originate from the catalysts but in the case of the presence of high amount of PMDI, it is not possible to identify the catalyst from the XPS data alone. ToF-SIMS data, however, show the presence of small intensities of PMDETA and DMCHA fragments. The intensity of PMDETA peaks on the failure surfaces of both sides is higher than in the bulk of foams for all foams. Gelation, which is liquid to rubber transition, is occurred for the PMDI, but a vitrification, which is liquid or rubbery to glassy transition as a result of an increase of average molecular weight and in the crosslink density of the material, can also happen during curing process, and 
these events depend on the cure temperature $\left(\mathrm{T}_{\mathrm{c}}\right)^{21-23}$. The glass transition temperature $\left(\mathrm{T}_{\mathrm{g}}\right)$ rises from the initial value to the ultimate glass transition temperature $\left(T_{g, u}\right)$ upon curing ${ }^{23}$. In general, the vitrification will occur when the $T_{c}$ is below the $T_{g, u}$, and the $T_{c}$ at the interface between the hot RPUF and the cold aluminium substrate might be lower than $\mathrm{T}_{\mathrm{g}, \mathrm{u}}$. The vitrification of polymer and enrichment of PMDETA at the interface possibly results in failure.

ToF-SIMS data recorded from the buried foam/aluminium interface area show that high concentrations of silicone surfactant fragments are observed within the cell region i.e. polymer/air interface, where it fulfils the important role of cell formation and stabilization, as a result of its low surface energy $y^{2,24-26}$. This silicone surfactant is not observed on the Foam 1/Al and Foam 3/Al interface regions. Because the silicone surfactant used in this work is a non-hydrolysable copolymer which has Si-C linkages instead of Si-O-C linkages ${ }^{27}$. Aluminium surface presents hydroxyl groups and adsorbed water, and thus the surfactant is not segregated at foam/aluminium interface i.e. polymer/water interface. Silicone surfactant fragments are observed on the interface region of Foam 2 sample, although these fragments are not observed on the aluminium side of the failure surface where Foam 2 only presents a layer some $1 \mathrm{~nm}$ in thickness. Foam 2 sample exhibits the highest taper section angle, and thus the selected interface region exhibits the least contribution from the interface region among all the foam samples. At the interface region, PMDI and PMDETA fragments are observed; in particular Foam 2 sample exhibits high PMDETA fragments at the interface region. High intensities of PMDI fragments are also observed on foam and cell regions while intensities of PMDETA fragments are small for these regions, and hence PMDETA is more concentrated at the RPUF/aluminium interface than the bulk. The migration of PMDETA to the surface of RPUF might be happening during the cream time when the RPUF mixture is still in a liquid form before the formation of cross-linking. The migration phenomenon can be occurred as a result of the compensation of chemical potential differences; high chemical potential of PMDETA within RPUF moves to the low chemical potential at the PMDETA/air interface ${ }^{28}$.

\subsection{Comparison of RPUF/aluminium and unfoamed PU/aluminium interfaces}

An unfoamed sample was analysed to study the behaviour of the catalysts without blowing agents and the surfactant. XPS analysis of the interfacial failure surfaces of 
the peeled sample reveals the presence of carbon, nitrogen and oxygen peaks on the PU side, whereas the aluminium side exhibits a high aluminium concentration (20.1\%) with relatively small carbon and nitrogen concentrations. High intensities of PMDETA and PMDI fragments are observed on the failure surface of aluminium side from ToF-SIMS data. These observations are all broadly consistent with the observations from the substrate failure surfaces of the foamed systems. Therefore, failure occurs near the interface but in the PU subsurface region. Compared with the failure surface of the unfoamed system, the PU failure surface exhibits less nitrogen (and $\mathrm{C}-\mathrm{N}$ bonding in the $\mathrm{C} 1 \mathrm{~s}$ spectrum) and higher oxygen (and $\mathrm{C}-\mathrm{O}$ bonding) than the bulk of unfoamed PU. ToF-SIMS data also show that the PU failure surface exhibits higher intensities of polyol fragments such as $101 \mathrm{u}\left(\mathrm{C}_{5} \mathrm{H}_{9} \mathrm{O}_{2}{ }^{+}\right), 113 \mathrm{u}$ $\left(\mathrm{C}_{6} \mathrm{H}_{9} \mathrm{O}_{2}^{+}\right)$and $115 \mathrm{u}\left(\mathrm{C}_{6} \mathrm{H}_{11} \mathrm{O}_{2}^{+}\right)$than the bulk Both XPS and ToF-SIMS results indicate that more polyol is present on the failure surface than in the bulk. The $\mathrm{AlCHNO}_{3}{ }^{-}$fragment is also observed on the failure surface of the aluminium substrate.

Ratios of the fragments at mass $106 \mathrm{u}$ to $132 \mathrm{u}$ of all failure surfaces and bulk regions are shown in Table 5, the ratios, taken from the specimens prepared by ULAM, of characteristic regions identified in the images of Figures 6(i) and 7(i) are also shown. The fragment characteristic of the isocyanate group at mass $132 \mathrm{u}$ originates from unreacted PMDI, while the mass $106 \mathrm{u}$ fragment (characteristic of an amine group) originates from reacted PMDI. The PMDI have several curing processes by reacting with active hydrogen groups such as water, polyol, amine, urea and urethane, and also with other isocyanate groups ${ }^{1}$. These peaks are observed from all reaction products and thus it is difficult to identify the cure reaction from the 106/132 ratio9. However, the previous paper shows that urea and urethane samples exhibit a high 106/132 ratio $^{9}$. Therefore, increase of the 106/132 cure ratio can imply occurrence of the PMDI reaction with water and/or polyol. The cure ratios are high on the failure surfaces, particularly the thin PU residues on the aluminium substrate, compared with the bulks of foams for all blowing systems, while the ratio of failure surface of unfoamed is lower than that of bulk of unfoamed. The bulk of unfoamed sample exhibits a higher cure ratio (106/132 diagnostic) than Foam 1 but lower than Foam 2 and 3. The bulk of RPUF samples contain cell areas and the cure ratios of cell areas are low, therefore, it is not appropriate to compare the ratios of bulk of Foam and unformed. Polyol fragments are observed on the failure surface of the unfoamed side and the bulk of unfoamed, their relative intensities being higher in the former 
case. These polyol fragments such as $101 \mathrm{u}\left(\mathrm{C}_{5} \mathrm{H}_{9} \mathrm{O}_{2}{ }^{+}\right), 113 \mathrm{u}\left(\mathrm{C}_{6} \mathrm{H}_{9} \mathrm{O}_{2}{ }^{+}\right)$and $115 \mathrm{u}$ $\left(\mathrm{C}_{6} \mathrm{H}_{11} \mathrm{O}_{2}^{+}\right)$, however, are not observed on all foam samples. Surfactants can help in mixing incompatible components by lowering the polyol/PMDI interfacial tension, and thus without the surfactant there may be insufficient mixing or, indeed, the PMDI might be reacting with itself ${ }^{24,29}$. The failure surfaces of the aluminium sides, where the outer extremity of the PU/aluminium interface region is present, exhibit the highest cure ratio. The implication being that the reaction proceeds more fully at the interface than in the bulks of PUs. This may give rise to a local stress concentration between the PU bulk where localised heating may occur as a result of the exothermic nature of the cure process, and the PU phase contacted with the aluminium where the temperature is lower than the PU bulk by adjacent to the cooled aluminium. In addition, the catalyst PMDETA is segregated at the interface and this may also accelerate the cure reaction. The ratio decreases from Foams 1 to 3 with decreasing water content, and Foam 3 has the smallest cure ratio. The lower cure ratio may be reflected in lower peel strength, and the ranking order is reflected in the relative peel strength for the foamed systems.

The interface regions (from the ULAM samples) of all foam samples generally exhibits higher cure ratio than the foam and the cell regions, and are significantly lower the values observed on the aluminium failure surfaces, although broadly similar to those observed in the bulk samples. A high intensity of the PMDETA fragment is observed on the foam and the cell regions of Foam 2 but not on other Foams. The cure ratios of Foams 1 and 3 are similar for all regions, although the bulk of Foam 3 exhibits smaller ratios than that of Foam 1. This is probably a result of the angle at which the taper section is cut. Foam 1 is cut at $17^{\circ}$ whilst Foam 3 is lower at $11^{\circ}$. Consequently the analysis of Foam 3 will have a greater contribution from the interface region in the angle spectrometer data. The cure ratio is high at the foam/aluminium interface and the ratio decreases towards the bulk of foam. For the unfoamed sample, the cure ratio of the interface region close to aluminium is higher than the interface region near unfoamed side. The interface region near the unfoamed side exhibits a high intensity of PMDETA fragment while the interface region close to aluminium side exhibit high intensities of PMDI fragments because the PMDI is the primary material of RPUF to react with hydroxyl groups and/or adsorbed water on the aluminium surface. 


\section{Conclusions}

The interface chemistry of RPUF/aluminium has been studied in order to understand adhesion mechanisms. Peel strength is the highest on the unfoamed sample while the lowest on the Foam 3. For all samples, the failure occurs very close to the interface between RPUF and aluminium. The catalyst PMDETA is concentrated at the failure surface and the failures occur in the enrichment of PMDETA layer where the migration of PMDETA might be happening at the beginning of the curing process. The cure ratio, which is the PMDI reaction with water and/or polyol, on the failure surface is also higher than that of the bulk of foam. A fragment indicative of covalent bond formation between PMDI and aluminium $\left(\mathrm{AlCHNO}_{3}{ }^{-}\right)$is observed at the interface between RPUFs and aluminium. The silicone surfactant is concentrated on the internal surface of the cell area to fulfil its role in cell formation and stabilisation, and the surfactant has not segregated at the RPUF/aluminium interface. For all foam systems, high C-O contents originating from polyol are observed from XPS data but ToF-SIMS data shows no presence of polyol fragments at high mass. This indicates that most of the polyols must have reacted with PMDI to form urethane bonds. For the unfoamed sample, however, some polyols have not reacted with PMDI as a result of the absence of the surfactants, which helps mixing incompatible components. 
Figures

(a)<smiles>CCCc1cc(N=C=O)ccc1Cc1ccc(N=C=O)cc1</smiles>

(b)<smiles>OCC(O)C(O)C(O)C(O)CO</smiles>

(c)<smiles>CN(C)CCN(C)CCN(C)C</smiles>

(d)<smiles>CN(C)C1CCCCC1</smiles>

(e)

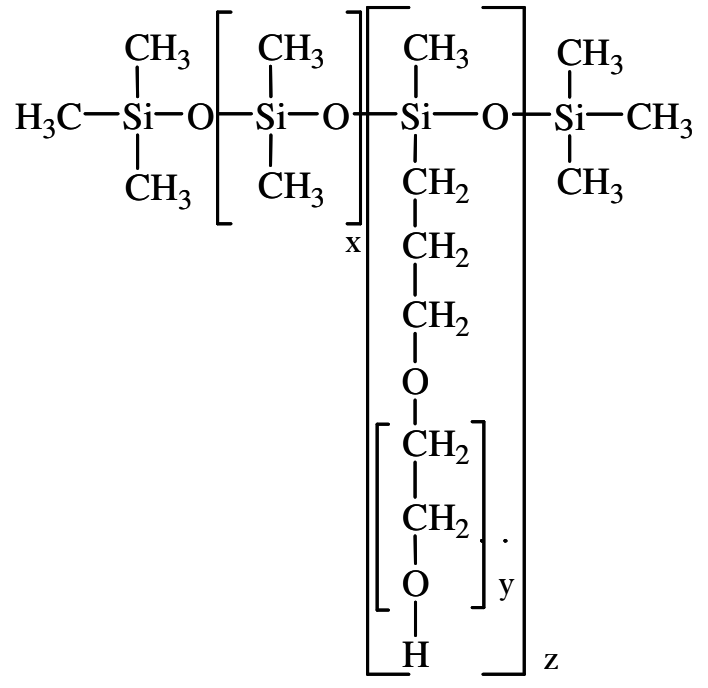


(f)

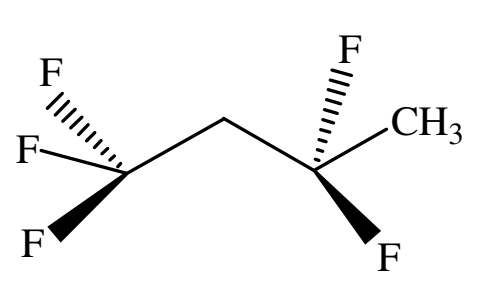

(g)

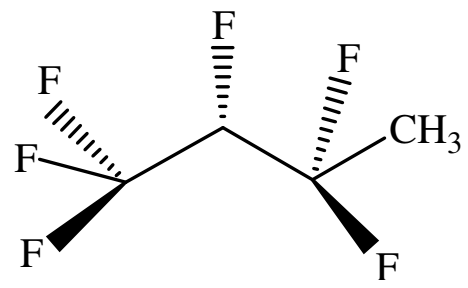

Figure 1: Structures of (a) PMDI, (b) polyhydroxyl initiator of polyol, (c) PMDETA, (d) DMCHA, (e) silicone surfactant copolymer ( $\mathrm{x}$ and $\mathrm{y}$ correspond to the average number of dimethylsiloxy and methylpolyethersiloxy groups per molecule, respectively. $\mathrm{z}$ indicates the average number of polyethylene oxide unit), (f) HFC-365mfc and (g) HFC-227ea 

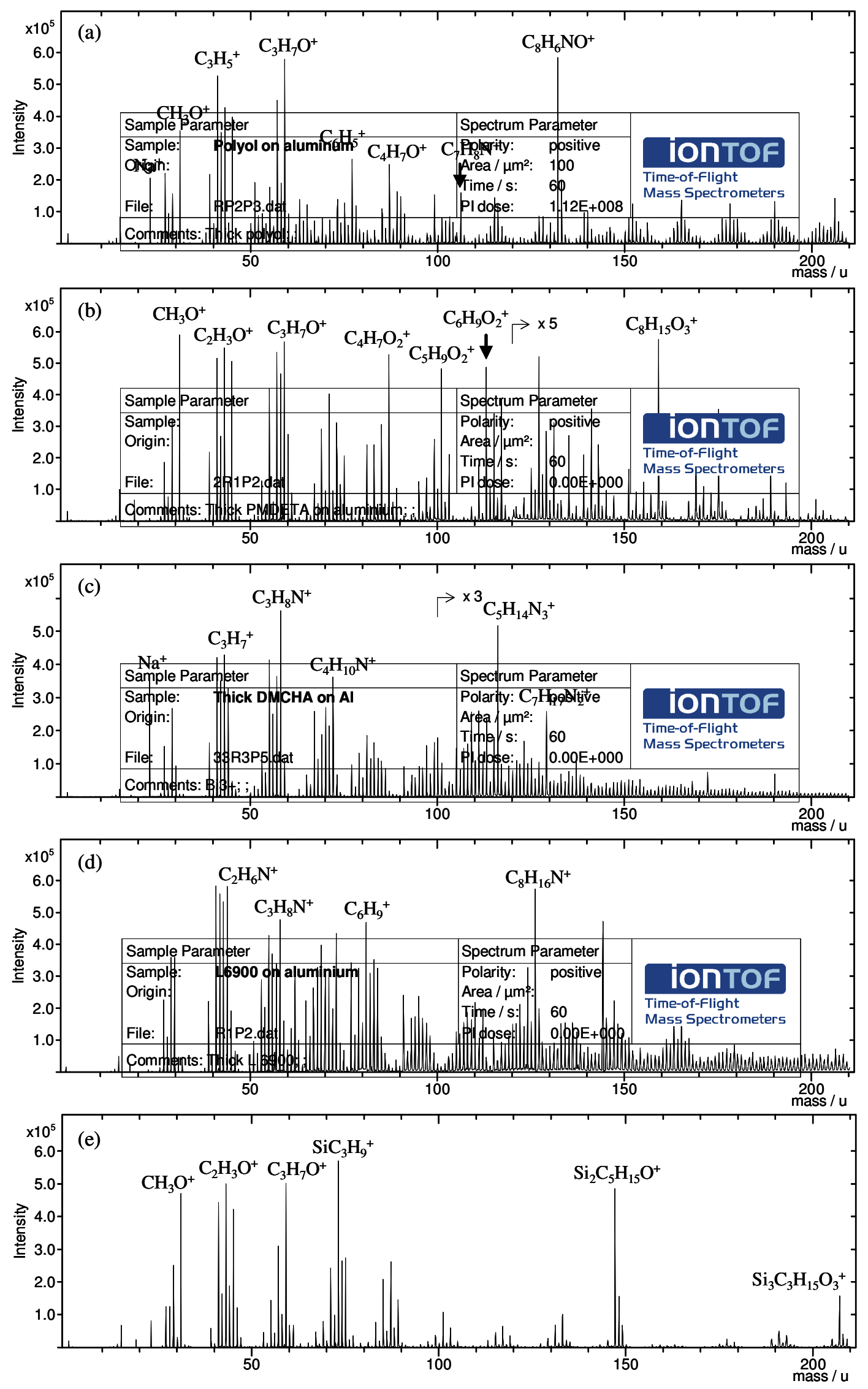

Figure 2: Positive ToF-SIMS spectra of raw materials: (a) PMDI, (b) polyol, (c) PMDETA, (d) DMCHA and (e) silicone surfactant 
(a)

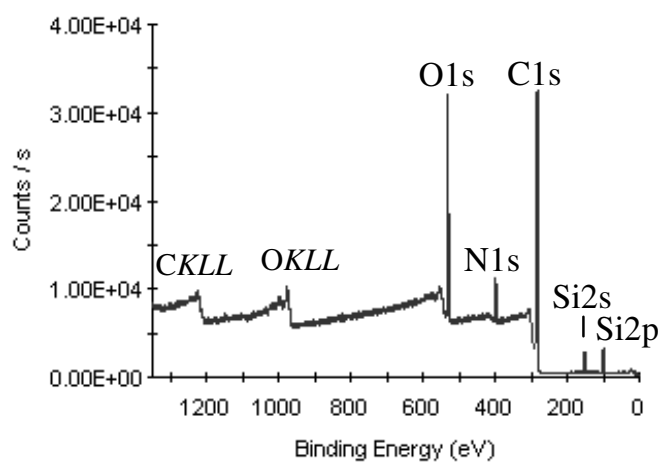

(c)

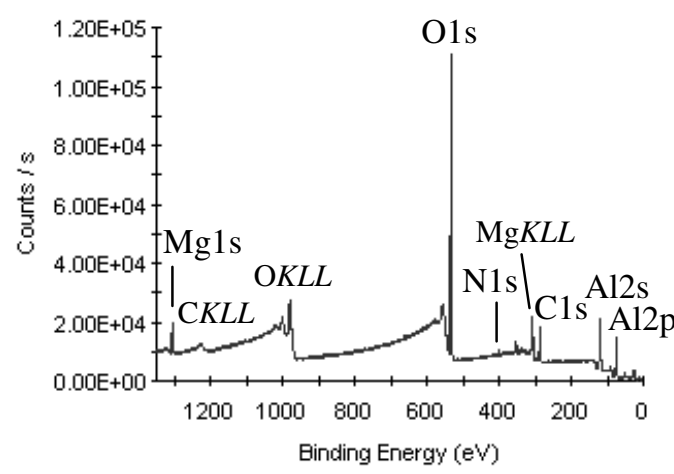

(b)

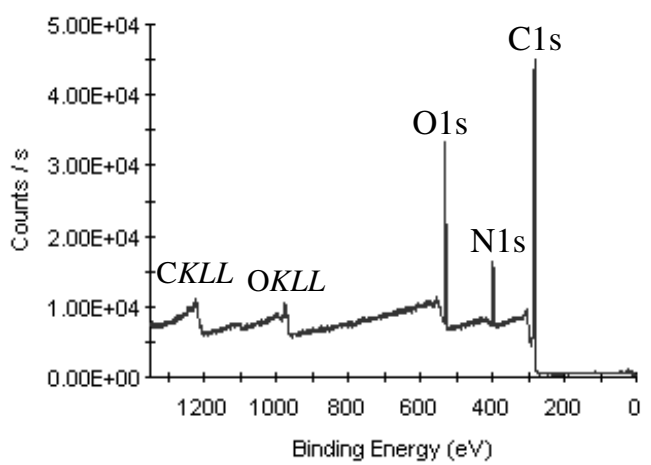

Figure 3: XPS survey spectra of (a) bulk surface of Foam1, (b) failure surface of Foam1 side and (c) failure surface of aluminium side 
(a)

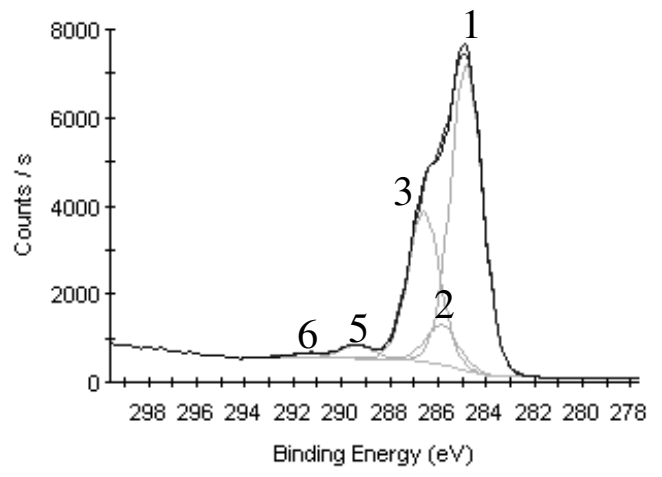

(c)

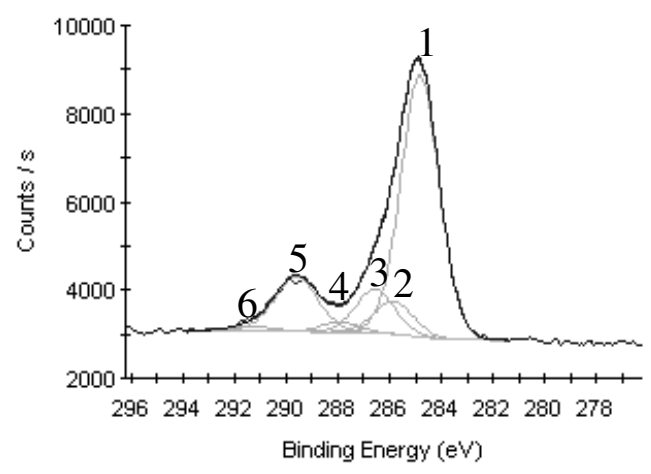

(b)

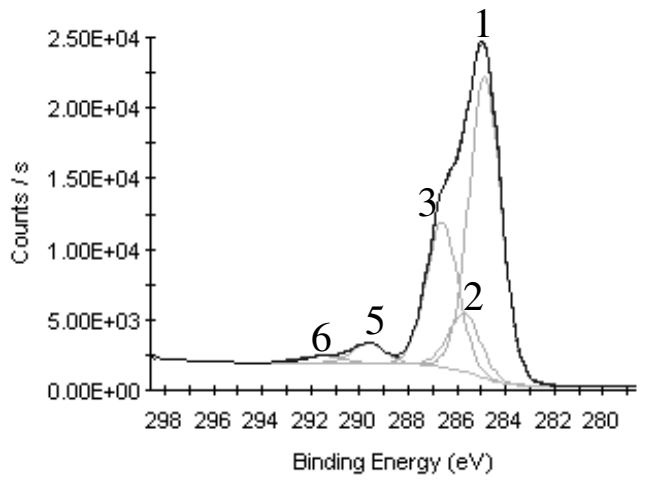

Figure 4: C1s peak fitting of (a) bulk surface of Foam 1, (b) failure surface of Foam 1 side and (c) failure surface of aluminium side 

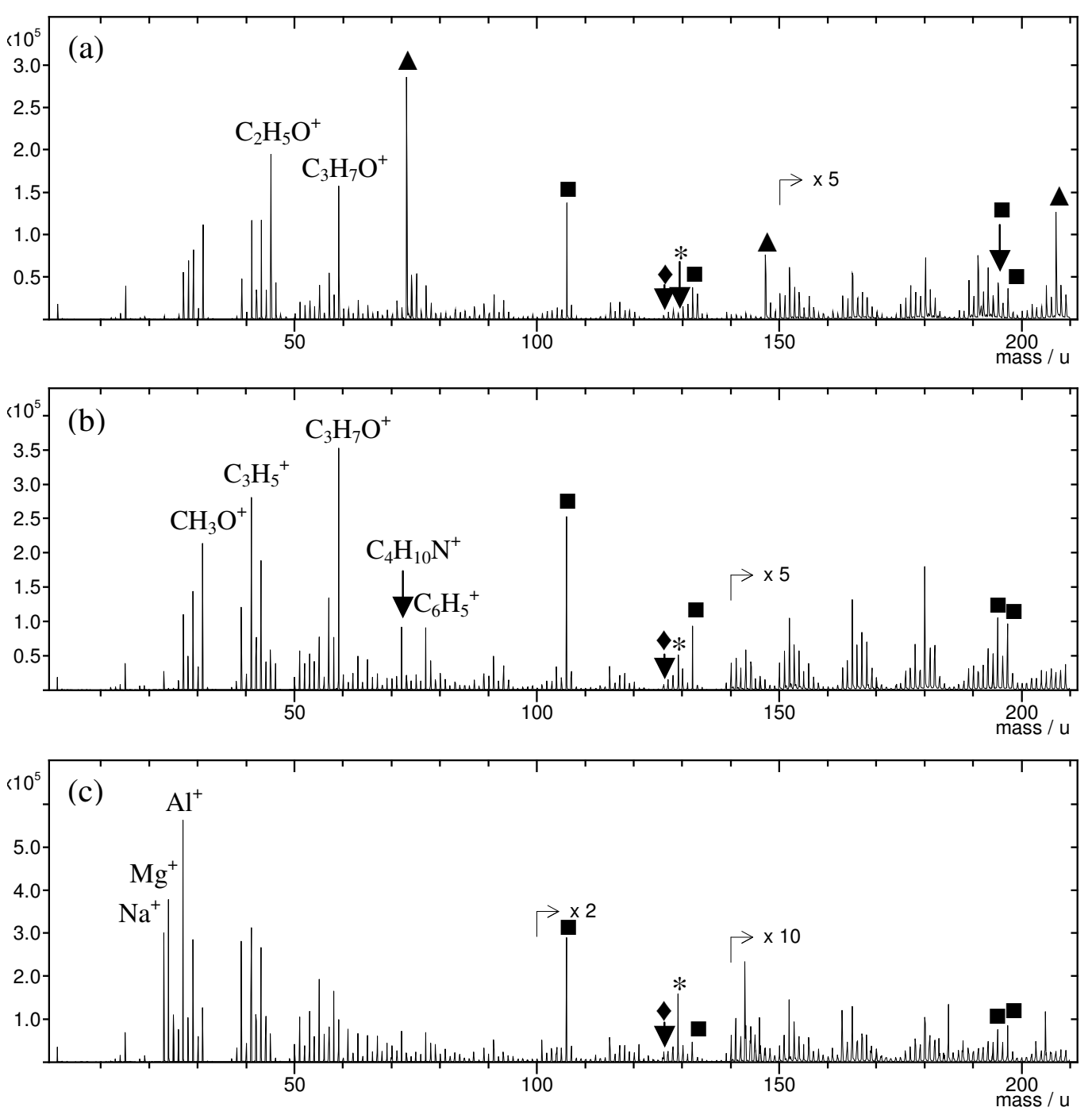

Figure 5: Positive ToF-SIMS spectra of (a) bulk surface of Foam 1, (b) failure surface of Foam 1 side and (c) failure surface of aluminium side of the peel failure. ( $\mathbf{m}$ : PMDI and reaction product of PMDI, $\boldsymbol{\Delta}$ : silicone surfactant, *: PMDETA and $\downarrow$ : DMCHA) 

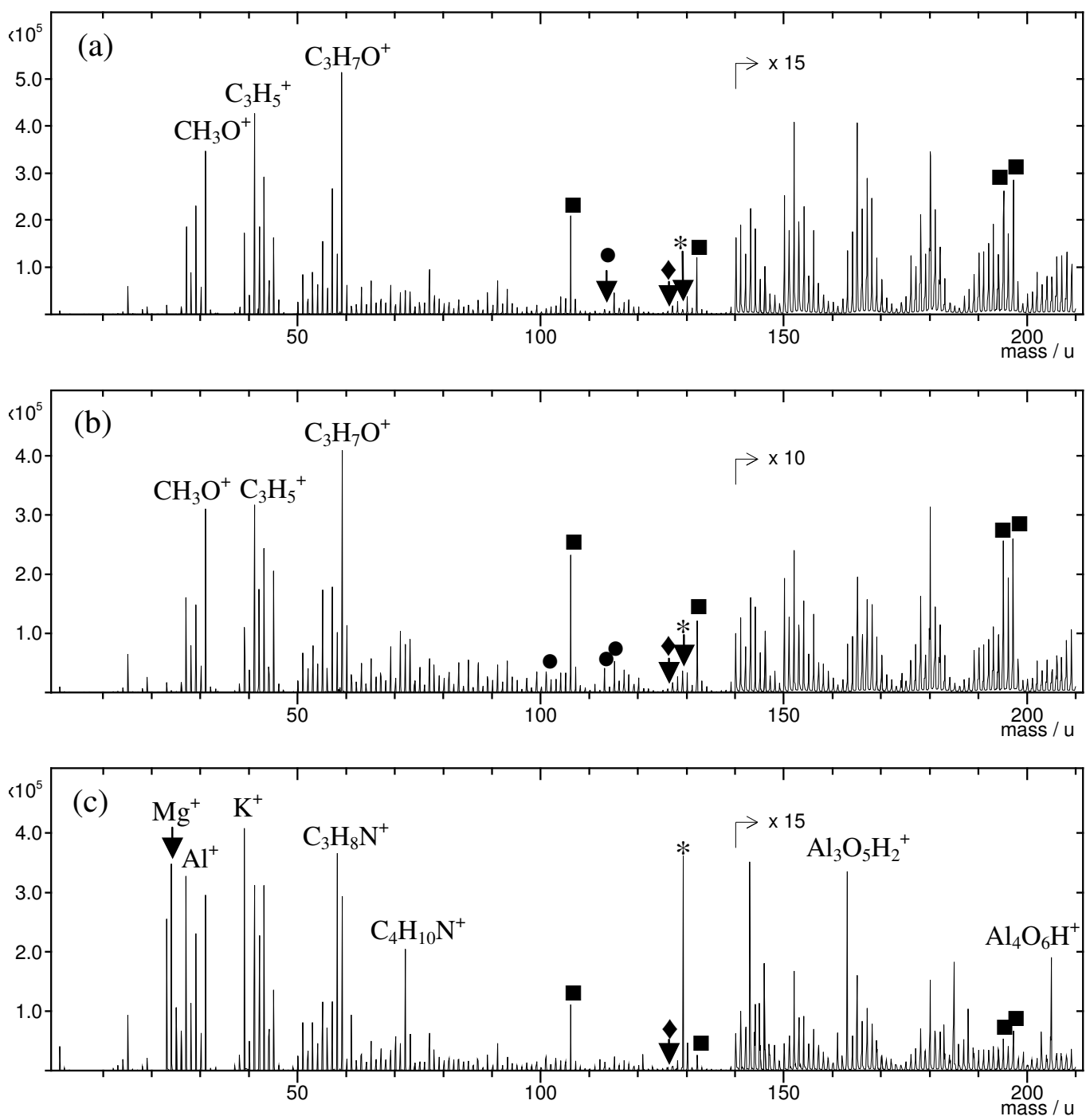

Figure 6: Positive ToF-SIMS spectra of (a) bulk surfaces of unfoamed sample, (b) failure surface of unfoamed PU side and (c) aluminium side of the peel failure. (m: PMDI and reaction product of PMDI, *: PMDETA, $\bullet$ : DMCHA and $\bullet$ : polyol) 
(a)

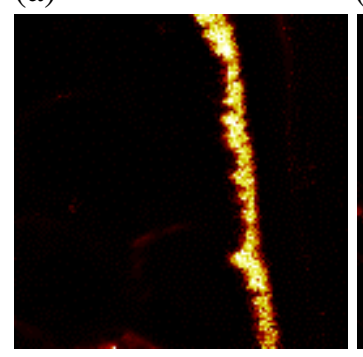

(d)

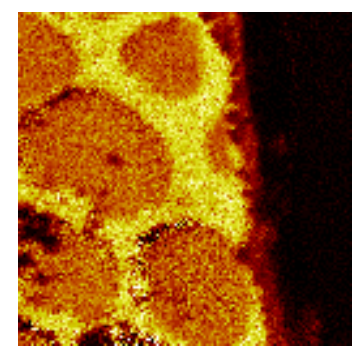

(g)

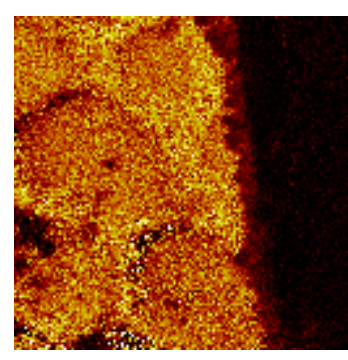

(b)

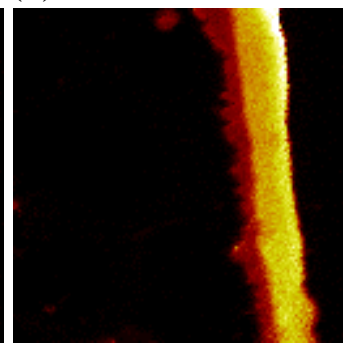

(e)

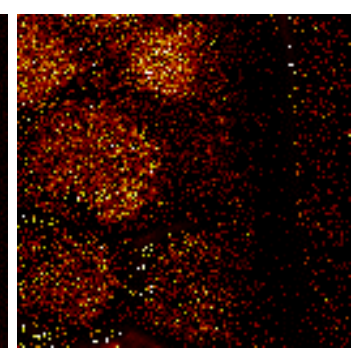

(h)

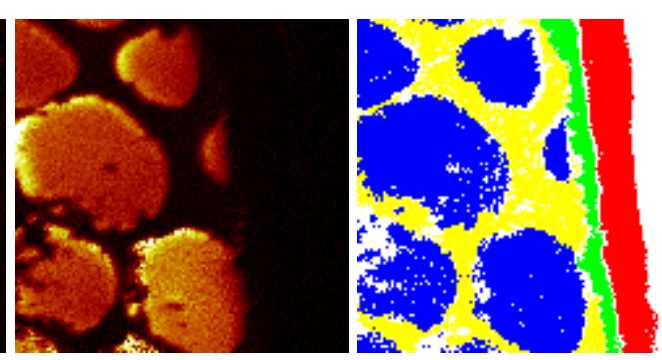

(c)

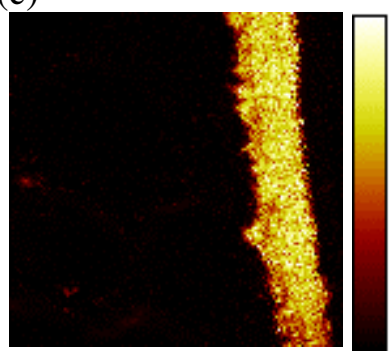

(f)

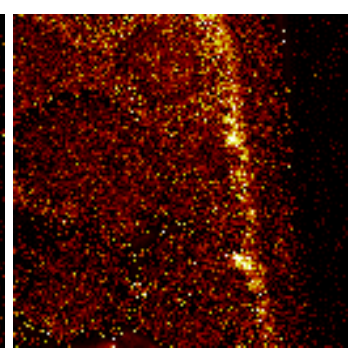

(i)

Figure 7: Normalized positive and negative ToF-SIMS images of the Foam 1/aluminium: (a) $\mathrm{Mg}^{+}(\mathrm{m} / \mathrm{z}=24 \mathrm{u})$, (b) $\mathrm{Al}^{+}(\mathrm{m} / \mathrm{z}=27 \mathrm{u}),(\mathrm{c}) \mathrm{AlO}_{2}^{-}(\mathrm{m} / \mathrm{z}=59 \mathrm{u}),(\mathrm{d}) \mathrm{C}_{7} \mathrm{H}_{6} \mathrm{~N}^{+}(\mathrm{m} / \mathrm{z}=106 \mathrm{u}$, (e) $\mathrm{C}_{8} \mathrm{H}_{16} \mathrm{~N}^{+}(\mathrm{m} / \mathrm{z}=126 \mathrm{u})$, (f) $\mathrm{C}_{7} \mathrm{H}_{17} \mathrm{~N}^{+}(\mathrm{m} / \mathrm{z}=129 \mathrm{u}),(\mathrm{g}) \mathrm{C}_{8} \mathrm{H}_{6} \mathrm{NO}^{+}(\mathrm{m} / \mathrm{z}=132 \mathrm{u})$, (h) sum of $\mathrm{C}_{3} \mathrm{H}_{9} \mathrm{Si}^{+}(\mathrm{m} / \mathrm{z}=73 \mathrm{u}), \mathrm{C}_{5} \mathrm{H}_{15} \mathrm{OSi}_{2}{ }^{+}(\mathrm{m} / \mathrm{z}=147 \mathrm{u})$ and $\mathrm{C}_{3} \mathrm{H}_{15} \mathrm{O}_{3} \mathrm{Si}_{3}{ }^{+}(\mathrm{m} / \mathrm{z}=207 \mathrm{u})$, and (i) selection of regions of interest (red: substrate region, green: interface region, yellow: foam region, blue: cell region), reconstructed spectra from these regions of interest are shown in Figure 8. Field of view is $500 \mu \mathrm{m} \times 500 \mu \mathrm{m}$. 
(a)

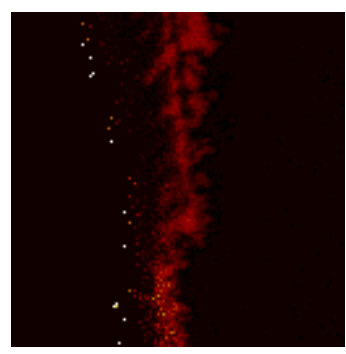

(d)

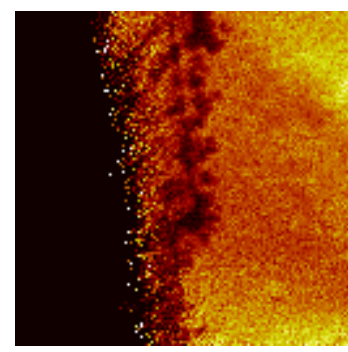

$(\mathrm{g})$

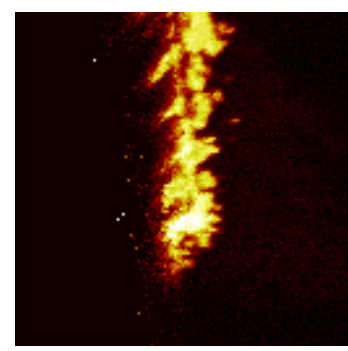

(b)

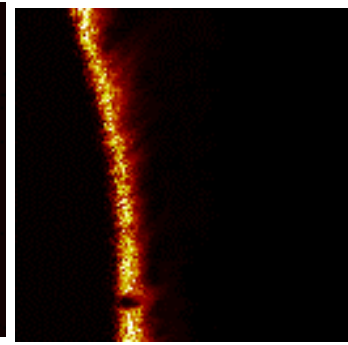

(e)

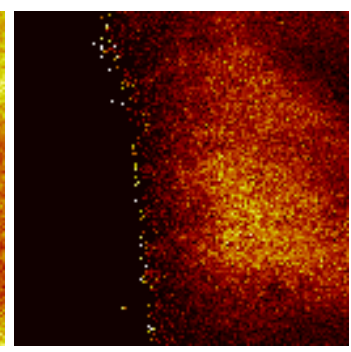

(h)

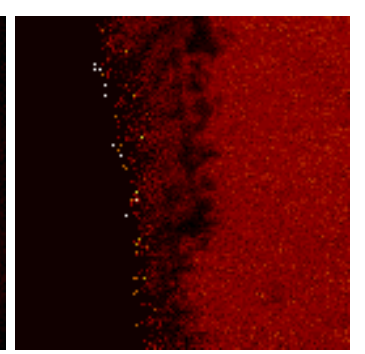

(c)

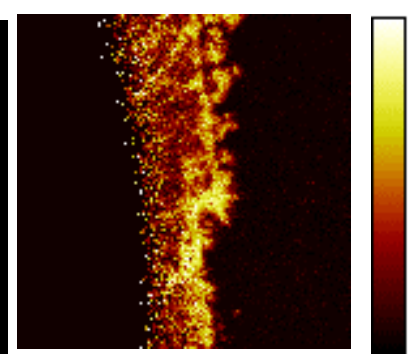

(f)

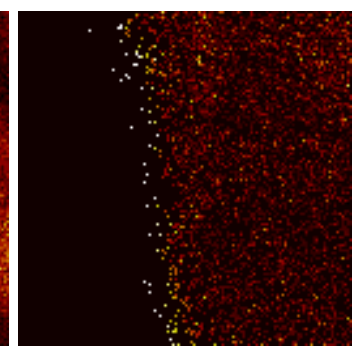

(i)

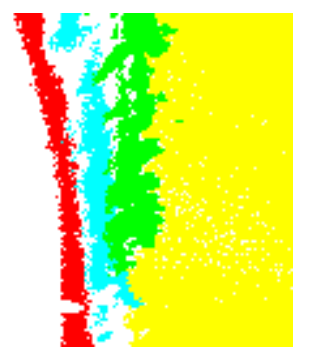

Figure 8: Normalized positive and negative ToF-SIMS images of the unfoamed/aluminium: (a) $\mathrm{Mg}^{+}(\mathrm{m} / \mathrm{z}=24 \mathrm{u})$, (b) $\mathrm{Al}^{+}(\mathrm{m} / \mathrm{z}=27 \mathrm{u})$, (c) $\mathrm{AlO}_{2}{ }^{-}(\mathrm{m} / \mathrm{z}=59 \mathrm{u})$, (d) $\mathrm{C}_{7} \mathrm{H}_{6} \mathrm{~N}^{+}(\mathrm{m} / \mathrm{z}=106 \mathrm{u})$, (e) $\mathrm{C}_{6} \mathrm{H}_{9} \mathrm{O}_{2}{ }^{+}(\mathrm{m} / \mathrm{z}=113 \mathrm{u})$, (f) $\mathrm{C}_{8} \mathrm{H}_{16} \mathrm{~N}^{+}(\mathrm{m} / \mathrm{z}=126 \mathrm{u}),(\mathrm{g}) \mathrm{C}_{7} \mathrm{H}_{17} \mathrm{~N}^{+}(\mathrm{m} / \mathrm{z}=129 \mathrm{u})$, (h) $\mathrm{C}_{8} \mathrm{H}_{6} \mathrm{NO}^{+}(\mathrm{m} / \mathrm{z}=132 \mathrm{u})$, and (i) selection of regions of interest (red: substrate region, light blue: interface region near substrate side, green: interface region near unfoamed PU, yellow: unfoamed ), reconstructed spectra from these regions of interest are shown in Figure 9. Field of view is $500 \mu \mathrm{m} \times 500 \mu \mathrm{m}$. 

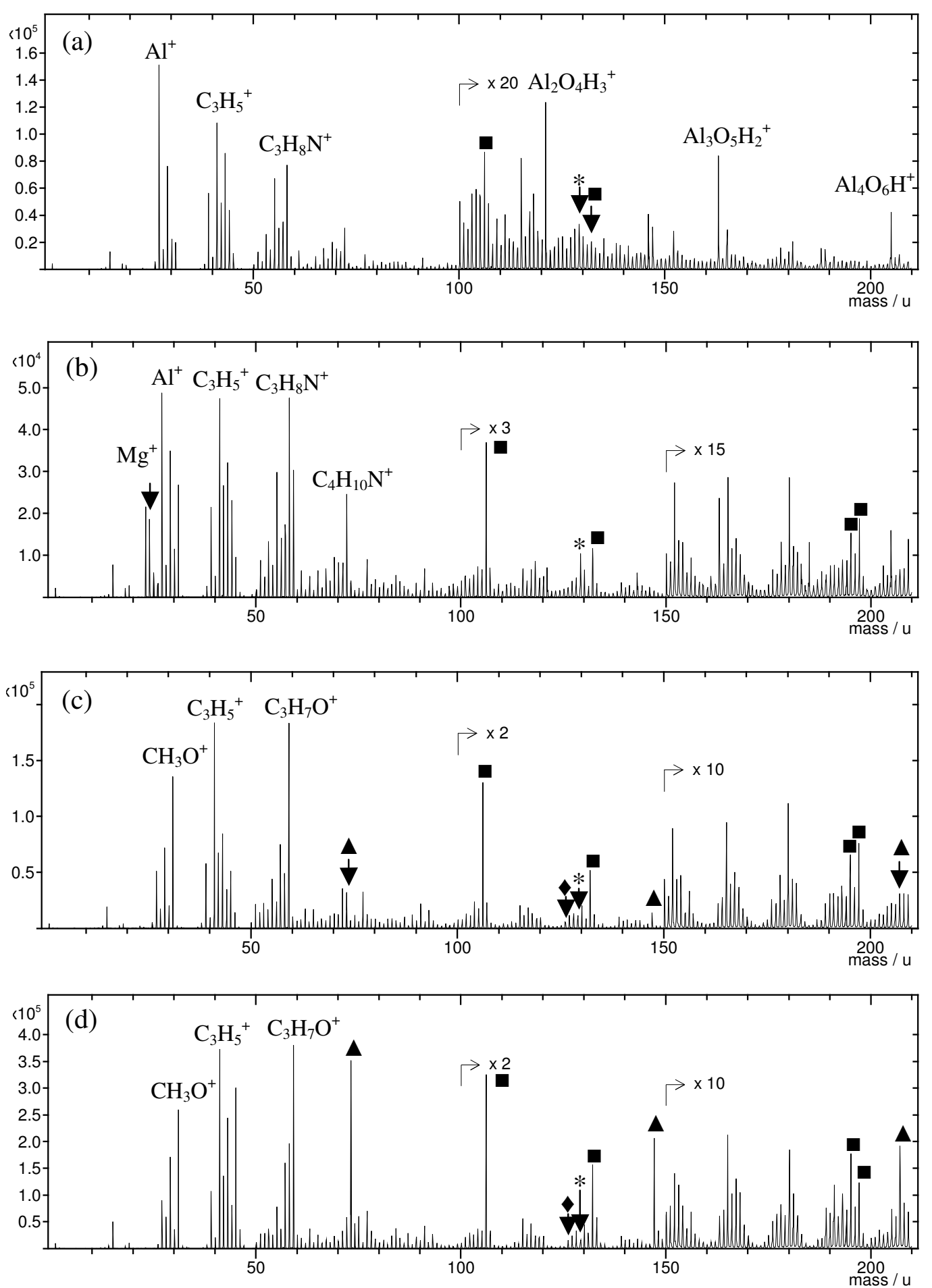

Figure 9: Reconstructed ToF-SIMS spectra of the Foam 1/aluminium interface region: (a) aluminium area (red), (b) interface area (green), (c) foam area (yellow) and (d) cell area (blue). Colours refer to the false colour image of Figure 6(i). ( $\mathbf{m}$ : PMDI and reaction product of PMDI, $\boldsymbol{\Lambda}$ : silicone surfactant, *: PMDETA and $\bullet$ : DMCHA) 

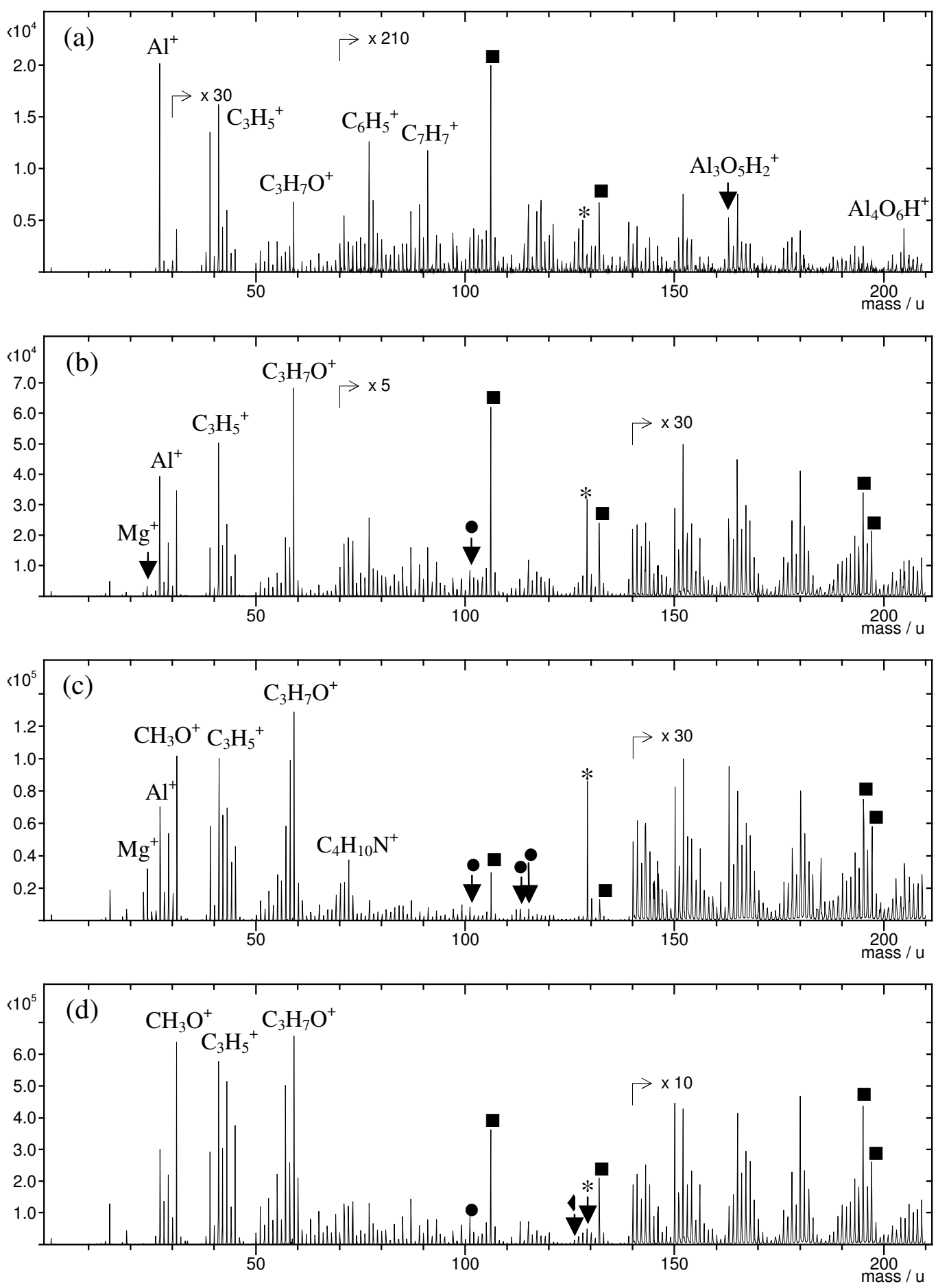

Figure 10: Reconstructed ToF-SIMS spectra of the unfoamed/aluminium interface region: (a) aluminium area (red), (b) interface area close to aluminium side (light blue), (c) interface area close to unfoamed PU side (green) and (d) unfoamed PU area (yellow). Colours refer to the false colour image of Figure 7(i). ( $\mathbf{m}$ : PMDI and reaction product of PMDI, *: PMDETA, DMCHA and $\bullet$ : polyol) 


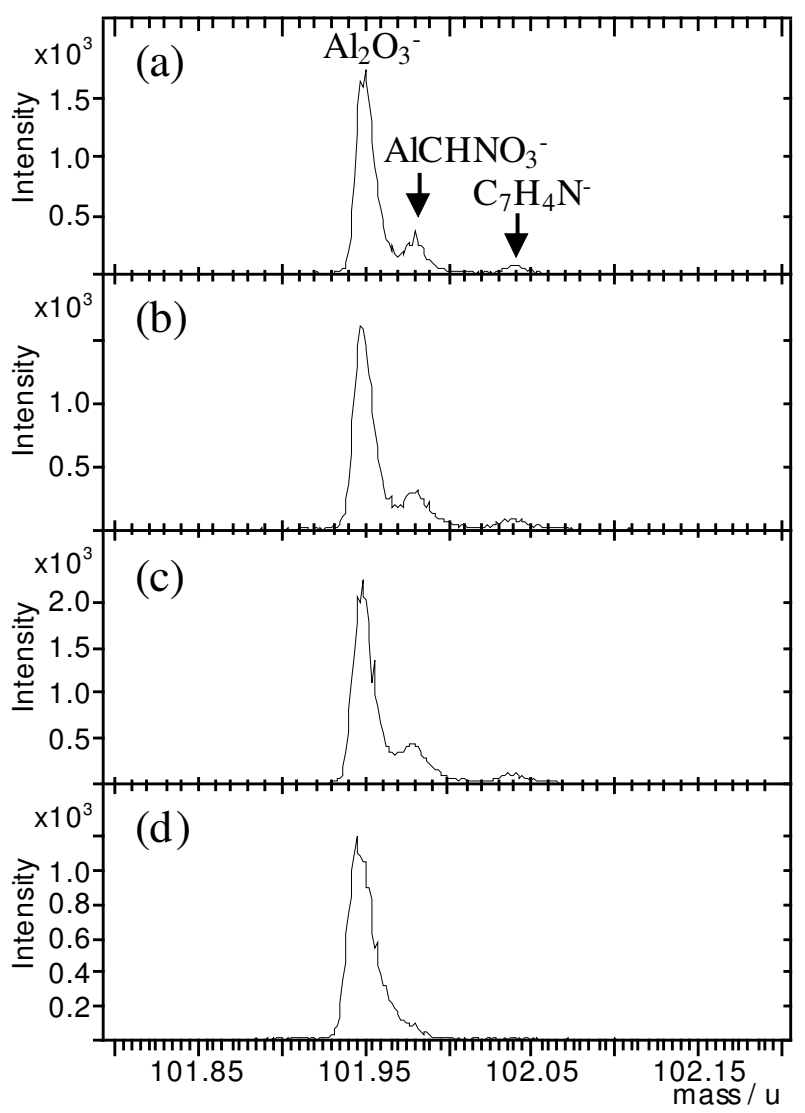

Figure 11: Spectra of nominal mass $\mathrm{m} / \mathrm{z}=102 \mathrm{u}$ at high resolution of failure surfaces of aluminium side for (a) Foam 1, (b) Foam 2 and (c) Foam 3, and (d) aluminium foil 


\section{Tables}

Table 1: Compositions of raw materials $(\mathrm{g})$

\begin{tabular}{|c|c|c|c|c|}
\hline \multicolumn{2}{|c|}{ Raw materials } & $\begin{array}{c}\text { Foam } 1 \\
\text { water blowing } \\
\text { system }\end{array}$ & $\begin{array}{c}\text { Foam } 2 \\
\text { mixed blowing } \\
\text { system }\end{array}$ & $\begin{array}{c}\text { Foam } 3 \\
\text { physical } \\
\text { blowing system }\end{array}$ \\
\hline \multicolumn{2}{|c|}{ Polyol } & 35.06 & 37.17 & 39.10 \\
\hline \multirow{2}{*}{$\begin{array}{l}\text { Amine } \\
\text { catalysts }\end{array}$} & PMDETA & 0.07 & 0.19 & 0.20 \\
\hline & DMCHA & 0.53 & 0.76 & 1.64 \\
\hline \multicolumn{2}{|c|}{ Silicone surfactant } & 0.70 & 0.76 & 0.78 \\
\hline \multirow{2}{*}{$\begin{array}{l}\text { Blowing } \\
\text { agents }\end{array}$} & Water & 1.58 & 0.84 & 0.39 \\
\hline & Solkane & None & 6.49 & 11.73 \\
\hline \multicolumn{2}{|c|}{ PMDI } & 62.06 & 52.78 & 46.17 \\
\hline
\end{tabular}

Table 2: Foams and failure surfaces of surface compositions (at. \%)

\begin{tabular}{llcccccc}
\hline Sample & & $\mathrm{C}$ & $\mathrm{N}$ & $\mathrm{O}$ & $\mathrm{Si}$ & $\mathrm{Al}$ & $\mathrm{Mg}$ \\
\hline Bulk of PU & Foam 1 & 69.2 & 5.5 & 21.0 & 4.3 & - & - \\
& Foam 2 & 67.1 & 4.6 & 23.7 & 4.6 & - & - \\
& Foam 3 & 67.6 & 3.7 & 24.4 & 4.5 & - & - \\
& Unfoamed & 72.4 & 5.7 & 21.9 & - & - & - \\
\hline PU side & Foam 1 & 73.5 & 7.7 & 18.8 & - & - & - \\
(Failure surface) & Foam 2 & 73.4 & 7.7 & 18.9 & - & - & - \\
& Foam 3 & 71.2 & 5.5 & 23.4 & - & - & - \\
& Unfoamed & 71.8 & 4.8 & 23.4 & - & - & - \\
\hline Aluminium side & Foam 1 & 16.5 & 1.3 & 59.3 & - & 20.2 & 2.7 \\
(Failure surface) & Foam 2 & 18.2 & 1.4 & 57.2 & - & 22.0 & 1.3 \\
& Foam 3 & 15.5 & 0.7 & 60.3 & - & 22.0 & 1.5 \\
& Unfoamed & 20.1 & 1.0 & 56.5 & & 21.1 & 1.4 \\
\hline Aluminium foil & & 9.8 & - & 63.5 & - & 24.8 & 1.9 \\
\hline
\end{tabular}


Table 3: Carbon functionalities with binding energies of bulk of foams and failure surfaces

\begin{tabular}{|c|c|c|c|c|c|c|c|}
\hline \multirow[b]{3}{*}{ Samples } & & \multicolumn{6}{|c|}{$\begin{array}{l}\text { Surface concentration of C1s peak fitting (at. \%) } \\
\text { (Binding energies of peak fitting }(\mathrm{eV}) \text { ) }\end{array}$} \\
\hline & & $1^{\text {st }}$ peak & $2^{\text {nd }}$ peak & $3^{\text {rd }}$ peak & $4^{\text {th }}$ peak & $5^{\text {th }}$ peak & $6^{\text {th }}$ peak \\
\hline & & $\begin{array}{l}\mathrm{C}-\mathrm{C} / \\
\mathrm{C}-\mathrm{H} / \\
\mathrm{C}-\mathrm{Si}\end{array}$ & C-N & $\begin{array}{l}\mathrm{C}-\mathrm{O} / \\
\mathrm{C}-\mathrm{O}-\mathrm{C}\end{array}$ & $\mathrm{C}=\mathrm{O}$ & $\begin{array}{c}\mathrm{N}=\mathrm{C}=\mathrm{O} / \\
\mathrm{N}-\mathrm{CN}=\mathrm{O} / \\
\mathrm{N}- \\
\mathrm{COH}=\mathrm{O} / \\
\mathrm{O}-\mathrm{C}=\mathrm{O}\end{array}$ & $\begin{array}{l}\text { Shake- } \\
\text { up } \\
\text { satellite }\end{array}$ \\
\hline \multirow[t]{4}{*}{ Bulk of PU } & Foam 1 & $\begin{array}{c}40.9 \\
(285.0)\end{array}$ & $\begin{array}{c}5.4 \\
(286.0)\end{array}$ & $\begin{array}{c}20.2 \\
(286.8)\end{array}$ & $\begin{array}{l}- \\
-\end{array}$ & $\begin{array}{c}1.9 \\
(289.6)\end{array}$ & $\begin{array}{c}0.8 \\
(291.6)\end{array}$ \\
\hline & Foam 2 & $\begin{array}{c}38.7 \\
(285.0)\end{array}$ & $\begin{array}{c}4.6 \\
(286.1)\end{array}$ & $\begin{array}{c}21.5 \\
(286.8)\end{array}$ & - & $\begin{array}{c}1.9 \\
(289.7)\end{array}$ & $\begin{array}{c}0.3 \\
(291.7)\end{array}$ \\
\hline & Foam 3 & $\begin{array}{c}36.2 \\
(285.0)\end{array}$ & $\begin{array}{c}3.7 \\
(286.0)\end{array}$ & $\begin{array}{c}25.6 \\
(286.8)\end{array}$ & - & $\begin{array}{c}1.9 \\
(289.7)\end{array}$ & $\begin{array}{c}0.2 \\
(291.8)\end{array}$ \\
\hline & Unfoamed & $\begin{array}{c}35.8 \\
(285.0)\end{array}$ & $\begin{array}{c}5.7 \\
(286.0)\end{array}$ & $\begin{array}{c}27.4 \\
(286.7)\end{array}$ & - & $\begin{array}{c}2.7 \\
(289.7)\end{array}$ & $\begin{array}{c}0.8 \\
(291.7)\end{array}$ \\
\hline \multirow[t]{6}{*}{$\begin{array}{l}\text { PU side } \\
\text { (Failure surface) }\end{array}$} & Foam 1 & $\begin{array}{c}41.5 \\
(285.0)\end{array}$ & $\begin{array}{c}8.1 \\
(285.9)\end{array}$ & $\begin{array}{c}20.0 \\
(286.8)\end{array}$ & $\begin{array}{ll}- \\
-\end{array}$ & $\begin{array}{c}2.8 \\
(289.8)\end{array}$ & $\begin{array}{c}1.1 \\
(291.6)\end{array}$ \\
\hline & Foam 2 & $\begin{array}{c}41.3 \\
(285.0)\end{array}$ & $\begin{array}{c}8.4 \\
(285.8)\end{array}$ & $\begin{array}{c}19.6 \\
(286.8)\end{array}$ & $\begin{array}{l}- \\
-\end{array}$ & $\begin{array}{c}2.9 \\
(289.8)\end{array}$ & $\begin{array}{c}1.2 \\
(291.9)\end{array}$ \\
\hline & \multirow{2}{*}{ Foam 3} & 34.4 & 6.7 & 27.1 & - & 2.4 & 0.7 \\
\hline & & $(285.0)$ & $(285.9)$ & $(286.8)$ & - & (289.8) & (291.7) \\
\hline & \multirow{2}{*}{ Unfoamed } & 34.9 & 4.7 & 29.4 & - & 2.3 & 0.5 \\
\hline & & $(285.0)$ & (286.1) & $(286.7)$ & - & (289.8) & $(292.0)$ \\
\hline \multirow[t]{4}{*}{$\begin{array}{l}\text { Aluminium side } \\
\text { (Failure surface) }\end{array}$} & Foam 1 & $\begin{array}{c}10.3 \\
(285.0)\end{array}$ & $\begin{array}{c}1.3 \\
(286.0)\end{array}$ & $\begin{array}{c}1.7 \\
(286.7)\end{array}$ & $\begin{array}{c}0.4 \\
(288.1)\end{array}$ & $\begin{array}{c}2.4 \\
(289.8)\end{array}$ & $\begin{array}{c}0.1 \\
(291.5)\end{array}$ \\
\hline & Foam 2 & $\begin{array}{c}11.0 \\
(285.0)\end{array}$ & $\begin{array}{c}1.3 \\
(285.9)\end{array}$ & $\begin{array}{c}2.5 \\
(286.6)\end{array}$ & $\begin{array}{c}0.4 \\
(288.3)\end{array}$ & $\begin{array}{c}2.1 \\
(290.0)\end{array}$ & $\begin{array}{c}0.2 \\
(291.9)\end{array}$ \\
\hline & Foam 3 & $\begin{array}{c}7.9 \\
(285.0)\end{array}$ & $\begin{array}{c}0.7 \\
(285.8)\end{array}$ & $\begin{array}{c}3.2 \\
(286.5)\end{array}$ & $\begin{array}{c}0.6 \\
(287.8)\end{array}$ & $\begin{array}{c}2.2 \\
(289.7)\end{array}$ & - \\
\hline & Unfoamed & $\begin{array}{c}11.8 \\
(285.0)\end{array}$ & $\begin{array}{c}0.9 \\
(286.0)\end{array}$ & $\begin{array}{c}4.8 \\
(286.7)\end{array}$ & $\begin{array}{c}0.6 \\
(287.9)\end{array}$ & $\begin{array}{c}1.9 \\
(289.9)\end{array}$ & - \\
\hline \multicolumn{2}{|l|}{ Aluminium foil } & $\begin{array}{c}5.9 \\
(285.0)\end{array}$ & $\begin{array}{l}- \\
- \\
\end{array}$ & $\begin{array}{c}1.3 \\
(286.5) \\
\end{array}$ & $\begin{array}{c}0.3 \\
(288.1) \\
\end{array}$ & $\begin{array}{c}2.3 \\
(289.9) \\
\end{array}$ & $\begin{array}{l}- \\
-\end{array}$ \\
\hline
\end{tabular}


Table 4: List of characteristic positive fragments originating from PMDI including reaction products of PMDI, polyol, DMCHA, PMDETA and silicone surfactant, and component assignments.

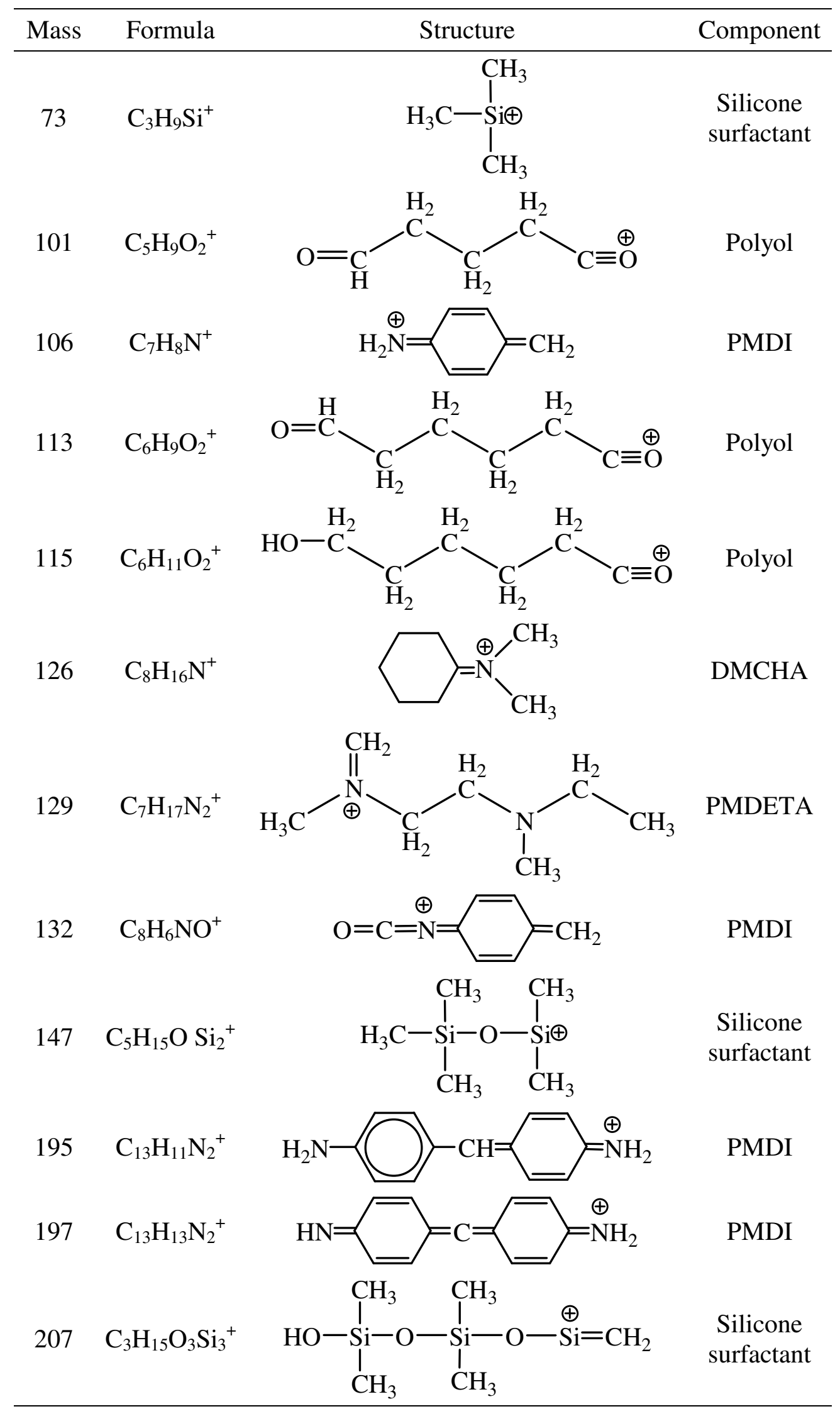


Table 5: Ratio of the intensity of the reacted PMDI fragment $(\mathrm{m} / \mathrm{z}=106 \mathrm{u})$ to that of the unreacted PMDI $(\mathrm{m} / \mathrm{z}=132 \mathrm{u})$ of bulk of foams and failure surfaces

\begin{tabular}{lcccc}
\hline \multirow{2}{*}{ Sample } & \multicolumn{4}{c}{$106 \mathrm{u} / 132 \mathrm{u}$ ratio } \\
\cline { 2 - 5 } & Foam 1 & Foam 2 & Foam 3 & Unfoamed \\
\hline Peeled samples & 2.8 & 2.2 & 1.6 & 2.6 \\
Bulk of foam/unfoamed & 4.1 & 3.7 & 3.1 & 2.2 \\
Foam/unfoamed side (Failure urface) & 7.2 & 6.6 & 6.4 & 6.5 \\
Aluminium side (Failure surface) & & & & \\
ULAM samples & 2.4 & 2.0 & 2.3 & \\
Cell area & 3.3 & 2.7 & 3.2 & 1.7 \\
Foam/unfoamed area & 4.2 & 2.8 & 4.4 & \\
Interface area & & & & 1.9 \\
Interface area near unfoamed side & & & & 2.2 \\
Interface area near aluminium side & 4.6 & 3.5 & 4.6 & 2.5 \\
Aluminium area & & &
\end{tabular}




\section{References}

1. D. Randall and S. Lee, The polyurethanes book, John Wiley \& Sons Ltd, Chichester UK, 2002.

2. S. H. Kim, H. Lim and B. K. Kim, Polym. Eng. Sci., 2008, 48, 1518.

3. H. Lim, S. H. Kim and B. K. Kim, eXpress Polym. Lett., 2008, 2, 194.

4. H. Singh, T. P. Sharma and A. K. Jain, J. Appl. Polym. Sci., 2007, 106, 1014.

5. K. H. Choe, D. S. Lee, W. J. Seo and W. N. Kim, Polym. J., 2004. 36, 368.

6. W. J. Seo, J. H. Park, Y. T. Sung, D. H. Hwang, W. N. Kim and H. S. Lee, J. Appl. Polym. Sci., 2004, 93, 2334.

7. J. Kim and E. Ryba, J. Adhes. Sci. Technol., 2001, 15, 1747.

8. H. Ulrich, Chemistry and Technology of Isocyanates, John Wiley \& Sons Ltd, Chichester UK, 1996, pp.434-437.

9. K. Shimizu, C. Phanopoulos, R. Loenders, M.-L. Abel and J. F. Watts, Surf. Interface. Anal., 2010, 42, 1432.

10. S. J. Hinder. C. Lowe, J. T. Maxted and J. F. Watts, Surf. Interface Anal., 2004, 36, 1575.

11. S. J. Hinder. C. Lowe, and J. F. Watts, Surf. Interface Anal., 2004, 36, 1032.

12. R. A. De Souza, J. Zehnpfenning, M. Martin and J. Maier, Solid State Ionics, 2005, 176, 1465.

13. J. F. Watts, A. Rattana and M.-L. Abel, Surf. Interf. Anal., 2004, 36, 1449.

14. M. M. Chehimi and J. F. Watts, J. Adhesion Sci. Technol., 1992, 6, 377.

15. G. Beamson and D. Briggs, High Resolution XPS of Organic Polymers - The Scienta ESCA300 Database -, John Wiley and Sons, Chichester, 1992.

16. Y. Deslandes, G. Pleizier, D. Alexander and P. Santerre, Polym., 1998, 39, 2361.

17. J. F. Watts and J. Wolstenholme, An introduction to Surface Analysis by XPS and AES, John Wiley and Sons, Chichester, 2003.

18. I. Olefjord, H. J. Mathieu and P. Marcus, Surf. Interf. Anal., 1990, 15, 681.

19. J. F. Watts, Surf. Interf. Anal., 1988, 12, 497.

20. S. Wu, Polymer interface and adhesion, Marcel Dekker, Inc., New York, 1982, pp.449-450.

21. J. Lange, N. Altmann, C. T. Kelly and P. J. Halley, Polym., 2000, 41, 5949.

22. H. Okabe, H. Nishimura, K. Hara and S. Kai, Prog. Theor. Phys. Suppl. 1997, 126, 119 
23. L. Barral, J. Cano, J López, P. Nogueira, C. Ramírez and M. J. Adab, Polym. Int., 1997, 42, 301

24. P. Mondal and D. V. Khakhar, J. Appl. Polym. Sci., 2004, 93, 2821.

25. J. M. Buist, Development in Polyurethane-1, Applied Science Publishers Ltd., London, UK, 1978, p.91.

26. A. Vaidya and M. K. Chaudhury, J. Coll. Interface Sci., 2002, 249, 235.

27. J. M. Buist and H. Gudgeon, Advances in Polyurethane Technology, Maclaren and Sons Ltd., London, UK, 1968, pp.197-198.

28. M.-L. Abel and J. F. Watts, Surf. Interf. Anal., 2009, 41, 508.

29. X. D. Zhang, C. W. Macosko, H. T. Davis, A. D. Nikolov and D. T. Wasan, J. Colloid Interf. Sci., 1999, 215, 270. 